Article

\title{
A Comparative Analysis of Coordination, Participation, and Training in Post-Disaster Shelter Projects
}

\author{
Aaron Opdyke ${ }^{1, * \mathbb{C}}$, Amy Javernick-Will ${ }^{2}$ and Matthew Koschmann ${ }^{3}$ \\ 1 School of Civil Engineering, University of Sydney, Sydney, NSW 2006, Australia \\ 2 Department of Civil, Environmental, and Architectural Engineering, University of Colorado Boulder, \\ Boulder, CO 80309, USA; amy.javernick@colorado.edu \\ 3 Department of Communication, University of Colorado Boulder, Boulder, CO 80309, USA; \\ koschmann@colorado.edu \\ * Correspondence: aaron.opdyke@sydney.edu.au; Tel.: +61-2-9351-3504
}

Received: 30 October 2018; Accepted: 13 November 2018; Published: 16 November 2018

\begin{abstract}
The delivery of post-disaster shelter assistance continues to be fraught with challenges derived from the coordination of resources, involvement of project stakeholders, and training of households and builders. There is a need to better understand what project elements in the delivery of post-disaster shelter projects most influence resilience and sustainability. To address this need, we examined nineteen post-disaster shelter projects in the Philippines following Typhoon Haiyan. We first characterized coordination, participation, and training employed across the planning, design, and construction phases of shelter projects and then used fuzzy-set qualitative comparative analysis (fsQCA) to assess the influence of these elements, alone and in combination, on building resilient and sustainable community infrastructure systems. Findings show that early involvement of households in planning efforts, combined with subsequent training, was important in evolving recovery outcomes. Our results point to the importance of: (1) supporting household sheltering processes over delivering hard products; (2) strategically linking project processes across phases; and (3) aligning humanitarian actions with long-term development. Conclusions from this study contribute to theory of sheltering in developing communities and more broadly to theory of recovery processes that link to community resilience and sustainability.
\end{abstract}

Keywords: resilience; sustainability; fuzzy-set qualitative comparative analysis; housing

\section{Introduction}

Disaster events continue to affect millions of people annually [1], disproportionately impacting developing countries [2]. Between 2008 and 2017, storms alone accounted for \$696 billion (USD) in damages [3]. Post-disaster, there is a pressing need to reconstruct shelter rapidly as it often forms the basis for re-establishing livelihoods, normalcy, and social ties. In this research, we use shelter to describe the spectrum of temporary or transitional dwellings that arise early in recovery efforts, exclusive of emergency shelter, such as tents and tarpaulins. While scholars draw the distinction between shelter and housing, pointing to the restoration of household activities and responsibilities as a crossover $[4,5]$, our work recognises the need to depart from well-defined definitional stages, recognising reality as a complex continuum of sheltering [6-8]. Despite significant advancements in post-disaster recovery over the last several decades, shelter after disaster remains one of the most complex and difficult tasks due to its socio-technical nature and unique, localized implementation. The effectiveness of recovery hinges on management of early processes and ensuring these efforts 
support long-term rehabilitation [9]. Our research seeks to unpack the evolution of shelter projects to understand how early processes lead to long term outcomes. We focus specifically on the outcomes of resilient and sustainable infrastructure, and three processes hypothesized to influence these outcomes: coordination $[10,11]$, participation [12,13], and training [14,15]. Each of these processes is a recurring theme in disaster scholarship due to their notable links to long-term outcomes.

We include coordination for its role in mobilizing resources from households, government agencies, and external organisations to reconstruct shelter. Furthermore, a unified approach to shelter leverages common goals following a disaster [16], avoids duplication of resources [17], and connects short-term planning with long-term risk reduction [18]. Previous research has also emphasized the importance of household participation $[13,19]$ in shelter projects, which has been shown to lead to higher satisfaction [20], improved social recovery [21], and, in some cases, has been found to counteract the negative influence of social vulnerability on recovery outcomes [22]. With a need for safer, more resilient shelter that continues to be maintained and used over time, training is also paramount in shelter projects. A growing body of research points to the need to include capacity building in humanitarian projects in order to ensure that households have the skills needed to maintain infrastructure or rebuild after future disasters [23,24].

While coordination, participation, and training have anecdotally been found to be important in shelter recovery, little research has formally operationalized these processes to understand how, and, importantly, when, they impact broader community outcomes. As a result, this research seeks to analyse what coordination, participation, and training processes are implemented in the delivery of post-disaster shelter construction across project phases of planning, design, and construction, and how these processes influence resilient and sustainable infrastructure systems in post-disaster recovery. Specifically, we will map these processes throughout rebuilding phases and compare and contrast these processes across multiple community projects to analyse how different processes, combined or in isolation, influence the resilience and sustainability of built infrastructure. Thus, we seek to address the following research question: What combinations of coordination, participation, and training in shelter project phases lead to sustainable and resilient infrastructure systems?

This paper first reviews the literature on resilience and sustainability infrastructure outcomes, making the case for differentiating between these constructs, before briefly reviewing coordination, participation, and training. Next, we describe the methods employed to operationalize and analyse these project processes in each phase of planning, design, and construction, as well as the methods used to analyse the impact of these processes on infrastructure resilience and sustainability outcomes within nineteen humanitarian shelter projects in the Philippines following Typhoon Haiyan. Finally, we discuss implications of our findings and conclude with recommendations for theory and practice.

\section{Background}

\subsection{Resilience}

Definitions of hazard resilience are diverse, yet disaster literature converges on two points: resilience is best conceptualized as a set of abilities or capacities, and it is better explained as adaptability, rather than stability [25]. In particular, we note that resilience is not static; it continues to change over time; however, indicators measured at a single point in time can predict how infrastructure, social, and economic systems will respond in the face of a future disaster.

Drawing from a systematic review of resilience literature [26], we created a multi-level assessment of hazard resilience based on four dimensions: (1) infrastructure; (2) governance; (3) economic; and (4) social. The focus of this study is on community infrastructure system resilience; we include these latter three dimensions due to their interconnectedness in supporting infrastructure resilience. Therefore, we collected and analysed data on 15 indicators across the four dimensions, shown below in Table 1 . A more thorough discussion of criteria used for the inclusion of these indicators can be found in the Supplementary Information, S1. 
Table 1. Resilience indicators.

\begin{tabular}{ll}
\hline Infrastructure & Governance \\
\hline [R1] Housing & [R9] Disaster Management Planning \\
a. Housing Design & [R10] Regional Cooperation \\
b. Housing Construction Quality & Economic \\
[R2] Water Access & {$[$ R11] Household Savings } \\
[R3] Sanitation Access & {$[$ R12] Employment } \\
[R4] Electrical Access & Social \\
[R5] Education Access & {$[R 13]$ Social Capital } \\
[R6] Medical Care Access & {$[R 14]$ Native to Community } \\
[R7] Transportation & {$[R 15]$ Community Organisations and Mobilization } \\
[R8] Evacuation Centres & \\
\hline
\end{tabular}

\subsection{Sustainability}

The second outcome of this study, sustainability of community infrastructure, has many definitions, but commonly focuses on economic, environmental, and social pillars. These dimensions are often tailored to specific sectors, and there are a growing number of indicators for each in construction projects in developing countries (e.g., [27]). In the context of this research, we define sustainability as capacities that promote continued use and functionality of infrastructure. We included six sub-indicators from literature, shown in Table 2, to assess the long-term sustainability of community infrastructure.

Table 2. Sustainability indicators.

\begin{tabular}{lll}
\hline \multicolumn{1}{c}{ Economic } & \multicolumn{1}{c}{ Social } & \multicolumn{1}{c}{ Environmental } \\
\hline [S1] Household Wealth & [S3] Land Tenure & [S5] Sanitation System \\
[S2] Service Interruptions & [S4] Shelter Satisfaction & [S6] Building Material Sourcing \\
\hline
\end{tabular}

Household wealth was selected for its prediction of resources to support maintenance of infrastructure assets. Service interruptions assess the frequency of disruptions to systems, and thus measure the ongoing functionality of services, such as water and electricity. Socially, we included land tenure, as it is intractably tied to the longevity of shelter [28]. Shelter satisfaction has been used as an indicator of the ability of shelter to meet household needs and services [29,30]. In this research we specifically compared satisfaction with pre-disaster shelter. For environmental sustainability, our indicators focused on the presence of a sanitation system to contain and treat wastewater, which, if not included, poses a significant health risk to the community. The availability and sourcing of building materials is also included, notably for its role in reducing the carbon footprint of construction [31].

In this study, we analyse resilience and sustainability as two unique outcomes, along with a third outcome, which encompasses both sustainability and resilience together. For example, consider a community that has utilised local materials, has regular access to uninterrupted services, and a track record of excellent maintenance of its infrastructure. In addition to other characteristics, we might consider this infrastructure sustainable. This same system may lack resilience if procedures are not in place to keep the services available following a disaster. Therefore, while sustainability and resilience may encompass the same system components, each is comprised of differing qualities. Operationalizing each outcome uniquely, and then in combination, provides insight as to the processes needed over time to obtain these coveted goals. Further discussion of the indicators selected can be found in Appendix A, Tables A4 and A5 and in the Supplementary Information, S1. 


\subsection{Project Factors Influencing Infrastructure Resilience and Sustainability}

We analysed three factors that arise during the planning, design, and construction of shelter projects that have potential to influence infrastructure outcomes. These include coordination of resources, participation of project stakeholders, and training of households.

\subsubsection{Coordination}

Previous research has highlighted that poor coordination in large-scale disasters, such as the 2010 Haiti earthquake, can result in deficiencies in recovery service provision [11]. The need to align and coordinate organisations when a disaster or crisis occurs is obvious; independent actions of one organisation without consideration of other organisations or sectors and their actions, can have severe negative consequences. Researchers have documented that coordination improves the recovery process [32], but not how coordination occurs across phases of the reconstruction process [16], nor how coordination in different phases of reconstruction impacts infrastructure outcomes. There is a need to unpack and analyse the impact of coordination during the planning and design phases of shelter projects on infrastructure outcomes.

\subsubsection{Participation}

The importance of participation of local actors in reconstruction has long been considered an important element of successful reconstruction projects [33]. There is, however, a lack of consensus on what is meant by 'participation', and there have been calls to operationalize and bring clarity to participation within post-disaster projects [13]. Past frameworks have sought to understand participation as a graduated scale, such as Arnstein's [34] "ladder of citizen participation", which was later expanded by Choguill [35]. However, while the literature has documented early participation well [36-38], participation during later stages has been less documented and remains disconnected from recovery outcomes.

Traditionally, participation is viewed as community members having a 'voice' in decisionmaking [39]. This view of participation focuses solely on political governance, neglecting to see participation as a project resource (e.g., knowledge, labour). These latter forms can become particularly important when considering multiple entities' goals, such as donor requirements, and their eventual effect on project performance [40]. Trends for participatory methods now commonly use 'participation' as a means to incorporate 'local knowledge' in the implementation of solutions, viewing local knowledge as a tangible object that can be extracted [41]. This approach lacks the consideration that 'people's knowledge' is actually formed and elicited through the planning process. To address these gaps, there is a need to operationalize the types of participation that occur in post-disaster infrastructure projects, attending to participation in different phases, to understand the types of participation that influence sustainable and resilient infrastructure outcomes.

\subsubsection{Training}

There has been increasing attention paid to involving multiple stakeholders in post-disaster reconstruction processes; however, it is important these parties possess fundamental skills in the tasks they are performing. Reconstruction often involves the incorporation of new building techniques that aim to reduce pre-disaster vulnerabilities, requiring designers, construction workers, governments, and community members to acquire new knowledge. This is not an easy task, considering the range of educational and socio-economic backgrounds of these parties. The training of the former of these, design and construction professionals, has been well studied, and knowledge management frameworks for these individuals have been proposed [14]. The training of the latter, governments and community members, has lacked attention and requires further study to understand the impact of such training in broader recovery outcomes [23]. Training is a critical step in transferring knowledge to stakeholders, not only in participatory processes of design and construction, but also in building capacity to enable 
community members and local governments to operate and maintain infrastructure systems. Broadly, the sparse study of training requires further exploration across projects to assess its benefits.

\section{Methods}

To analyse coordination, participation, and training in the planning, design, and construction phases of post-disaster shelter projects, and determine how these elements combine to contribute to resilient and sustainable infrastructure, we employed fuzzy set qualitative comparative analysis (fsQCA), which has a growing presence in disaster scholarship [15,42-44]. We selected fsQCA because it bridges the divide between in-depth case studies and statistical analysis by drawing upon set theory and fuzzy logic (Ragin 2000). Notably, the method retains in-depth knowledge of complexity within cases in analysis, offering the ability to generalize findings through robust comparisons [45]. In addition, QCA allows for "equifinality", meaning that multiple paths or solutions to the same outcome may coexist.

In fsQCA, an outcome of interest is first identified, in this case, resilience and sustainability of community infrastructure systems, then "conditions" are identified that are posited to influence the outcome, such as coordination. Outcomes are roughly equivalent to dependent variables and conditions similar to independent variables in statistical analysis; however, QCA retains unique methodological terminology, and the two should not be conflated. Furthermore, while statistical methods rely on correlational measures, QCA uses a set-theoretic approach.

\subsection{Research Context}

We analysed reconstruction processes longitudinally within communities affected by Typhoon Haiyan in the Philippines. In November 2013, Haiyan damaged and destroyed over 1.1 million homes and affected more than 16 million people [46]. The storm sustained wind speeds of $315 \mathrm{kph}$ (196 mph) and gusts of up to $380 \mathrm{kph}(235 \mathrm{mph})$, making it the strongest storm to ever make landfall [47]. Making matters worse, in 2012, a year before Haiyan, the Eastern Visayas region where the storm first made landfall had the second highest poverty rate in the Philippines at 37.4\% [48]. Organisations delivered shelter assistance to households using a wide variety of approaches, which provided an opportunity to comparatively examine project elements and assess their impact on recovery outcomes.

We selected nineteen shelter reconstruction projects across three regions in the central Philippines for in-depth, longitudinal investigation. Specifically, we selected communities that experienced similar levels of damage, that were of comparable size, and that displayed variation in reconstruction strategies employed by organisations so as to 'theoretically sample' the three proposed conditions-coordination, participation, and training [49,50]. Project locations are shown in Figure 1.

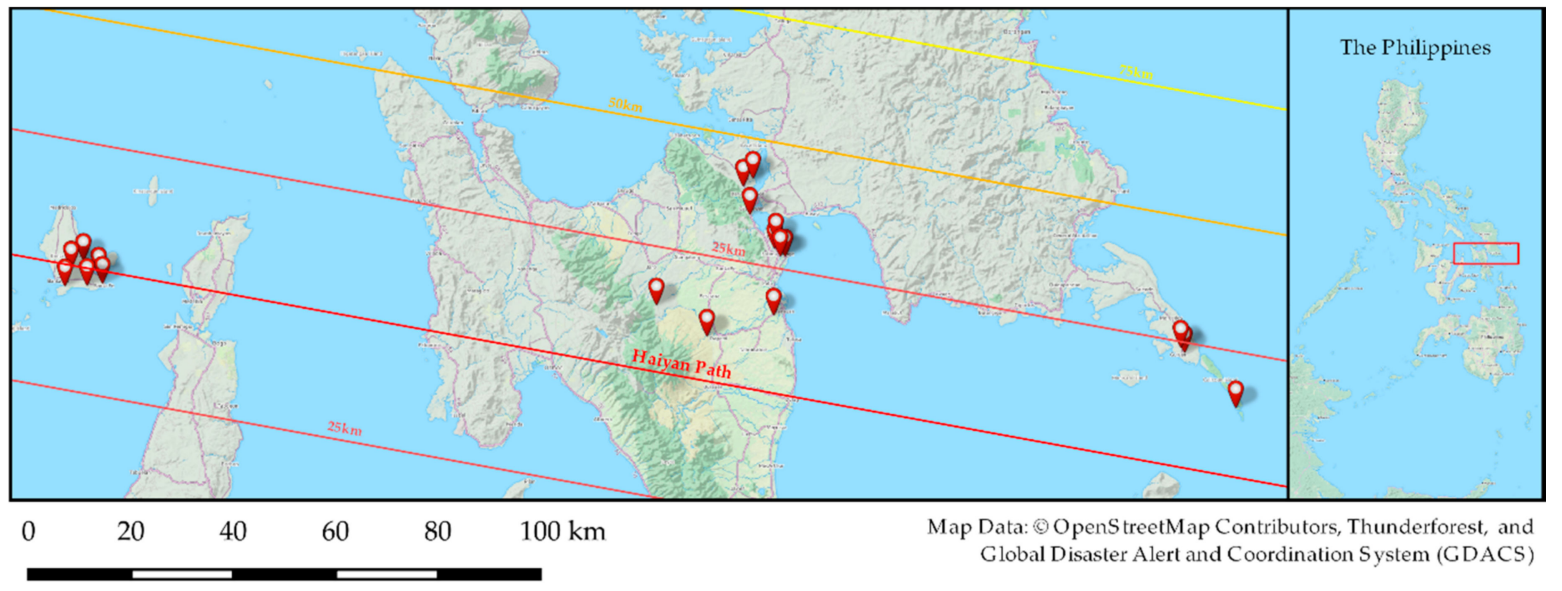

Figure 1. Project locations. 
We selected an embedded unit of analysis of a project within a community and bounded our study at the barangay level—the lowest political division in the Philippines. The communities represented larger cases, whose stakeholders included government officials, non-government organisations (NGOs), and households receiving shelter assistance. Those involved in supplying funding, expertise, resources, or maintenance of the constructed shelter and broader infrastructure represented the bounded system of the case [51,52]. We excluded households receiving shelter assistance from other organisations outside of the primary project considered within a community. For example, in one community there were three organisations assisting households with shelter assistance; we bounded our analysis to only those households receiving assistance by the organisation we identified for inclusion in the study. A list of the communities selected, and shelter assistance details, are provided in Table 3.

Table 3. Project and community overview.

\begin{tabular}{ccccccc}
\hline Case & Community & Municipality & Province & Population & $\begin{array}{c}\text { Households } \\
\text { Assisted }\end{array}$ & $\begin{array}{c}\text { Shelter } \\
\text { Categories }\end{array}$ \\
\hline 1 & Okoy & Santa Fe & Cebu & 3532 & 230 & 3 \\
2 & Maricaban & Santa Fe & Cebu & 2999 & 118 & 6 \\
3 & Poblacion & Santa Fe & Cebu & 2345 & 40 & 3,6 \\
4 & Sungko & Bantayan & Cebu & 3296 & 183 & 1,2 \\
5 & Sillon & Bantayan & Cebu & 4064 & 75 & 3 \\
6 & Kangkaibe & Bantayan & Cebu & 2635 & 348 & 3,6 \\
7 & Tagpuro & Tacloban City & Leyte & 677 & 86 & 2 \\
8 & Pago & Tanauan & Leyte & 917 & 365 & 6 \\
9 & New Kawayan (101) & Tacloban City & Leyte & 543 & 148 & 1 \\
10 & Bagacay (93) & Tacloban City & Leyte & 3936 & 150 & 3 \\
11 & San Agustin & Jaro & Leyte & 824 & 45 & 3 \\
12 & San Jose (83C) & Tacloban City & Leyte & 2548 & 42 & 3 \\
13 & Magallanes (52) & Tacloban City & Leyte & 1304 & 199 & $1,2,3,4,5$ \\
14 & San Jose (85) & Tacloban City & Leyte & 1572 & 234 & 1 \\
15 & Hiabangan & Dagami & Leyte & 958 & 165 & 1,3 \\
16 & Sagkahan (62) & Tacloban & Leyte & 1434 & 484 & $1,3,4,5$ \\
17 & Sulangan & Guiuan & Eastern Samar & 3597 & 63 & 1,3 \\
18 & Cogon & Guiuan & Eastern Samar & 1146 & 133 & 2,6 \\
19 & Cantahay & Guiuan & Eastern Samar & 1118 & 105 & 3 \\
\hline
\end{tabular}

Shelter categories: 1 Repair and retrofit; 2 Transitional shelter; 3 Core/progressive shelter; 4 Rental subsidies; 5 Hosting support; 6 Resettlement.

We categorized the type of shelter assistance provided within each community into six modalities that included: (1) repair and retrofit; (2) transitional shelter; (3) core/progressive shelter; (4) rental subsidies; (5) hosting support; and (6) resettlement. Repair and retrofit assistance upgraded and strengthened damaged dwellings. Transitional shelter assistance provided interim shelter on the path toward permanent housing. Similarly, core shelters sought a similar aim, but accomplished this through a single room structure that could be expanded. Progressive shelter is similarly used to describe basic units that are intended for incremental expansion. Rental subsidies and hosting support both provided cash assistance to aid households in seeking rental units or support for shared shelter with family hosts. Finally, resettlement involved permanent reconstruction on new sites away from coastal hazards. Examples of shelter are shown in Figure 2. While some projects were initially intended to be temporary, these often became 'permanent,' complicated by issues of land tenure. Similarly, several projects crafted as permanent solutions became interim dwellings. The terminology we use above to describe projects provides a framework to examine the type of assistance provided, but as will be discussed below, the reality of these approaches often departed from their intentions. 


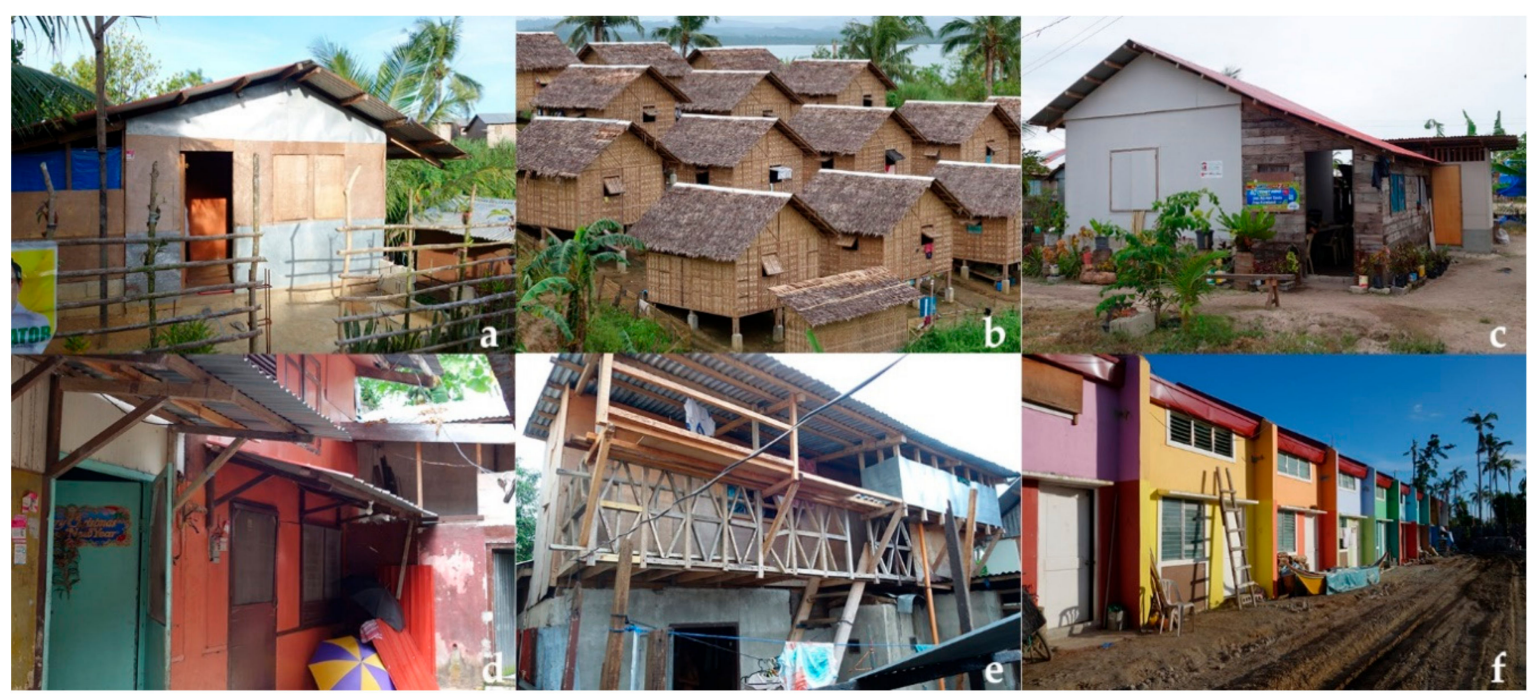

Figure 2. Example Shelter Typologies: (a) repair and retrofit; (b) transitional shelter; (c) core/progressive shelter; (d) rental subsidies; (e) hosting support; (f) resettlement.

\subsection{Data Collection}

For each of the shelter projects selected, we collected interview, documentation, and observation data during field visits at $6,13,28$, and 36 months' post-disaster. During our first field visit, which spanned four months, we conducted 32 semi-structured interviews with non-governmental (NGO) staff, local government officials, and community members involved in infrastructure reconstruction within the selected communities. Interviewees stemmed from international and domestic NGOs, local government units (LGUs), the Shelter Cluster, and the Water, Sanitation, and Hygiene (WASH) Cluster. Interview questions during this initial fieldwork focused on understanding how coordination of resources was occurring and what stakeholders were participating in these efforts. Example interview questions included: "How is your organisation currently coordinating rebuilding efforts with other NGOs and local governments?" and "How are you involving beneficiaries in your shelter projects?" In addition to interviews, field notes were recorded from daily observations of reconstruction projects and cluster coordination meetings. These notes encompassed dialogue that occurred during meetings and observation of stakeholder interactions in on-site planning activities. For example, observed participation of households was noted during construction activities and later compared to interview statements. Finally, cluster policy documents, meeting minutes, recovery plans, and technical communication documents were also collected.

A second, three-month field visit was conducted four months later, during which an additional 167 interviews were conducted with households, government officials, and aid organisations. Individuals were selected based on continuing reconstruction efforts in projects identified during the first phase. Questions again centred on types of coordination, participation, and training that were occurring, with specific attention to coordination and participation within the design phase and participation and training within the construction phase. Example questions to organisations included, 'What is being requested of beneficiaries during construction?' and 'Is your organisation providing training to households and, if so, how?' Example questions to beneficiaries included, 'Who designed or make decisions regarding your house floorplan and features?' and 'Can you describe any training provided?'.

Our third, three-month field visit occurred post-project completion. During this visit, we collected data on shelter project outcomes to capture indicators of resilience and sustainability. In-person, verbal surveys, were administered with translators who recorded responses on a tablet. In total, 320 surveys across the nineteen shelter projects were administered. Questions asked households to assess their access to infrastructure services, such as water, sanitation, power, education, medical care, transportation, and evacuation centres and collected household demographic data, such as family size and income. Households were also asked to assess the quality of their shelter and the researchers 
noted the condition of each household surveyed. An additional 40 surveys were also administered to local government officials to assess disaster management planning and cooperation with neighbouring barangays and municipalities. A final two-week field visit was completed to follow up on missing data and triangulate conflicting information through 12 additional interviews with organisation staff and households. All interview guides and surveys can be found in Supplementary Information, S2.

\subsection{Data Analysis}

Interview responses were translated, transcribed, and then imported into NVivo qualitative analysis software. First, responses were deductively coded into the three primary conditions-coordination, participation, and training - which were pre-selected for analysis based on their theorized importance in literature. To unpack these further, and to align with emerging theory of shelter project management after disasters (e.g., [53]), we opted to further situate and code coordination, participation, and training into project phases of planning, design, and construction. Within each of those codes, we then inductively coded themes that emerged across the studied projects for each condition and phase, which became sub-conditions. For instance, cross-sector integration, the inclusion of livelihood, WASH, or disaster risk reduction (DRR) into the studied shelter projects, emerged as a sub-condition of coordination during the planning phase. Two researchers independently completed the coding to identify and verify the themes, or sub-conditions in the data [54], as well as the extent of presence of these identified themes within each case. Inter-rater reliability scores in the form of Cohen's Kappa coefficient were then computed for comparison on a $20 \%$ sample of interviews with all values in excess of 0.4 -the common threshold considered acceptable [55].

\subsection{Conditions and Sub-Conditions across Project Phases}

\subsubsection{Planning}

For the planning phase of projects, we considered two separate conditions: (1) coordination and (2) participation. Coordination was operationalized through three sub-conditions that surfaced during qualitative coding of interviews, which included shelter sector participation, cross-sector integration, and land rights. Shelter sector participation was defined as the involvement of the primary shelter project organisation in Shelter Cluster activities, such as data reporting and meetings. The Shelter Cluster is one of thirteen existing humanitarian clusters responsible for facilitating coordination after disasters in humanitarian crises. The body functions through collective action of humanitarian organisations and organises meetings and resources for shelter partners. Cross-sector integration considered whether WASH, livelihood, or disaster risk reduction (DRR) activities were included with shelter support. Finally, land rights determined whether the organisation or households (depending on who was leading early planning), considered and secured land tenure agreements for the expected lifespan of planned shelter. In the case of temporary or transitional projects, this period was often two to five years.

Participation also varied during the planning phase of projects, with two sub-conditions emerging from qualitative coding. The household's ability to select location was found to be one of the key tasks during planning. Additionally, determination of aid, or the process through which resources and their distribution were determined, varied in household participation. For some projects, this meant directly assessing and involving households in deciding the type of assistance needed (e.g., shelter, medical support), while others pre-determined the assistance from donor requirements.

\subsubsection{Design}

For the design phase, we again considered the same two separate conditions as for planning: (1) coordination, and (2) participation. During design, coordination activities were operationalized through the provision of WASH in shelters and the application of uniform design standards developed by the Shelter Cluster. Provision of WASH was included because of its ability to capture the integration of one key sector into the design of shelters. The second component of coordination, the application of 
uniform design standards, considered whether the shelter organisation followed collectively decided standards, such as the Shelter Cluster's '8 Key Messages' or, in some cases, the National Structural Code of the Philippines.

Within design, participation consisted of household floorplan and layout decisions and government permitting of designs by municipal agencies. For floorplan and layout, high household participation involved deciding configurations of shelter elements, whereas its absence was prescribed designs implemented by organisations. While government participation was largely absent from planning in shelter projects, government permitting of shelter designs emerged as an area of participation during the design phase. This consisted of municipal agencies reviewing designs and suggesting modifications to better suit household needs, such as additional doors for expanding structures.

\subsubsection{Construction}

During the construction phase, two process conditions were identified: (1) participation and (2) training. We omitted coordination during this phase as intra-organisational communication waned after design for all projects studied. Participation emerged from four sub-conditions, consisting of sweat equity, material procurement, household financial management, and oversight. Sweat equity, or labour contributions, varied greatly across projects-some lacked any formal requirements and others mandated up to $2000 \mathrm{~h}$ per household. Material procurement was another area of observed household participation, where materials were obtained by the beneficiary. Alternatively, projects directly procured materials, often for logistical, efficiency, or quality control reasons. Household financial management, the participation of households in controlling resources during construction, emerged as a sub-condition from the interviews. Practical examples of this included cash transfers, where the household would hire labour and oversee the project's budget. Lastly, oversight surfaced from interviews and has been identified in research literature as an area of participation during construction (e.g., [22]). While most organisations inspected construction, some projects also afforded households the ability to participate in verifying construction quality.

Previous research has analysed the influence of training on construction knowledge retention, based upon the principles of safer construction disseminated by the Shelter Cluster and found that retention of knowledge was achieved through a diversity of methods employed by formal training programs or observation of construction by the beneficiary [20] (Opdyke et al., 2018). Thus, we included two sub-conditions for training during construction that included diversity of methods and on-site observations. Diversity of methods captured whether the training used multiple methods to educate households and builders on new construction techniques. For example, we considered whether lectures, demonstrations, and technical drawings were used in combination or isolation. On-site observations captured whether the households were present on the construction site. Further detail on our calibration across all three phases can be found in Appendix A, Tables A1-A3 and in the Supplementary Information, S1.

\subsection{Variable Calibration}

Calibrating raw data is a vital step in QCA research that contextualizes variables to make measurements interpretable, consistent, and logical. Using existing theory and case knowledge, anchor points for membership and non-membership were set for each sub-condition and a level of precision for the set was selected based upon classifications that emerged from the qualitative coding summaries [56].

For example, we calibrated household participation in floorplan and layout, an important process of stakeholder participation mentioned in literature and practice during the design phase, by the degree of household involvement in determining dwelling configurations. Households that were never consulted and given a prescribed design were defined as non-membership and assigned a value of 0 . Households that had active voice in deciding floorplans and control over final decisions were assigned as full membership and assigned a value of 1 . Between these scenarios, we identified consultations 
that were conducted through large community meetings, which were assigned a value of 0.33 , and households that were consulted individually on select features such as the placement of windows and doors, but not more substantive features, which were assigned a value of 0.66 . A key distinction was the crossover of having individual control of design elements. While this example highlights a 4-score set, other fuzzy sets, such as dichotomous crisp sets $(0 / 1)$, were used based on theoretical and case knowledge. We then averaged any sub-conditions within a primary condition and phase. Continuing our example above, household participation in floorplan and layout was averaged with government permitting to assign an overall score for stakeholder participation during the design phase.

\subsection{Outcomes}

Our outcomes of interest were resilience, sustainability, and the combination of resilience and sustainability. We collected data for the indicators outlined earlier, in Tables 1 and 2, and drew from literature to define sub-indicators. For example, we identified that shelter design and construction quality were two important factors for overall contributions of shelter to infrastructure resilience.

After calibrating each sub-outcome for resilience and sustainability, we averaged within each dimension and then averaged across dimensions to aggregate to a single resilience and sustainability fuzzy score for each case. In most cases, we selected to average sub-outcomes, as we anticipate some measured characteristics are able to compensate for others. For example, for the social dimension of resilience, high social capital among households may compensate for the lack of community organisations, allowing for similar levels of social mobilization. In two instances, however, we opted to select the minimum values. In the case of aggregating housing design and quality sub-outcomes, we took the minimum value, as both were considered equally important in contributing to the resilience outcome. Furthermore, when considering the combined outcome of resilience and sustainability, we also took the minimum value for each case. By taking a minimum value of each independent outcome, we assume that the combined outcome cannot exist without the presence of both. Once we calibrated our macro conditions and outcomes, we then assembled our truth table, displaying the calibrated numerical value for each condition in each community. Our truth table is shown below in Table 4.

Table 4. Resilience and sustainability truth table.

\begin{tabular}{|c|c|c|c|c|c|c|c|c|c|}
\hline Community & PlanCoord & PlanPart & DesCoord & DesPart & ConstPart & ConstTrain & Resilience & Sustain & Combined \\
\hline Okoy & 0.78 & 0.70 & 0.67 & 0.67 & 0.17 & 1.00 & 0.59 & 0.70 & 0.59 \\
\hline Maricaban & 0.68 & 0.00 & 0.33 & 0.00 & 0.50 & 0.50 & 0.36 & 0.60 & 0.36 \\
\hline Poblacion & 0.44 & 0.00 & 0.00 & 0.00 & 0.50 & 0.00 & 0.46 & 0.22 & 0.22 \\
\hline Sungko & 0.11 & 1.00 & 0.00 & 0.00 & 0.35 & 0.00 & 0.47 & 0.45 & 0.45 \\
\hline Sillon & 0.44 & 0.00 & 0.33 & 0.00 & 0.50 & 0.00 & 0.35 & 0.37 & 0.35 \\
\hline Kangkaibe & 1.00 & 0.00 & 0.33 & 0.00 & 0.50 & 0.50 & 0.39 & 0.67 & 0.39 \\
\hline Tagpuro & 0.44 & 0.00 & 0.33 & 0.00 & 0.50 & 0.00 & 0.40 & 0.21 & 0.21 \\
\hline Pago & 0.46 & 0.00 & 0.33 & 0.00 & 0.50 & 0.50 & 0.29 & 0.37 & 0.29 \\
\hline New Kawayan (101) & 0.22 & 1.00 & 0.00 & 0.00 & 0.85 & 0.84 & 0.69 & 0.73 & 0.69 \\
\hline Bagacay (93) & 0.78 & 0.00 & 0.33 & 0.00 & 0.17 & 1.00 & 0.43 & 0.69 & 0.43 \\
\hline San Agustin & 0.22 & 0.00 & 0.33 & 0.00 & 0.34 & 0.34 & 0.39 & 0.27 & 0.27 \\
\hline San Jose (83C) & 0.78 & 1.00 & 0.33 & 0.67 & 0.50 & 0.50 & 0.68 & 0.85 & 0.68 \\
\hline Magallanes (52) & 1.00 & 1.00 & 1.00 & 0.67 & 1.00 & 0.50 & 0.42 & 0.45 & 0.42 \\
\hline San Jose (85) & 0.57 & 1.00 & 0.00 & 0.00 & 0.67 & 1.00 & 0.42 & 0.65 & 0.42 \\
\hline Hiabangan & 0.68 & 1.00 & 0.00 & 0.00 & 0.50 & 0.84 & 0.72 & 0.75 & 0.72 \\
\hline Sagkahan (62) & 1.00 & 1.00 & 1.00 & 0.67 & 0.50 & 0.67 & 0.73 & 0.88 & 0.73 \\
\hline Sulangan & 0.78 & 0.70 & 1.00 & 0.67 & 1.00 & 1.00 & 0.58 & 0.59 & 0.58 \\
\hline Cogon & 0.56 & 0.00 & 0.33 & 0.00 & 0.50 & 0.00 & 0.50 & 0.42 & 0.42 \\
\hline Cantahay & 0.67 & 0.00 & 0.00 & 0.33 & 0.85 & 1.00 & 0.30 & 0.38 & 0.30 \\
\hline
\end{tabular}

\subsection{Analysing Causal Pathways}

We then used fsQCA software [57] to analyse pathways. We assessed the usefulness of pathways using two metrics: consistency and coverage. Consistency measures the degree to which cases with a given set of conditions exhibit the outcome, where a consistency score of 0.8 is required, shown below in Equation 1. Coverage measures the degree to which a given pathway explains the cases 
analysed, indicating the relevancy of each pathway [58], shown below in Equation 2. During this analysis, we also determined which individual conditions were necessary or sufficient to produce the outcome, where necessity is a measure of the degree to which the outcome is a subset of the causal condition and sufficiency provides a measure of the degree to which the causal condition is a subset of the outcome. We conducted this analysis for both resilience and sustainability independently, and then in combination.

$$
\begin{gathered}
\text { Consistency }=\frac{\sum \min \left(X_{i} Y_{i}\right)}{\sum X_{i}} \\
\text { Necessity }=\frac{\sum \min \left(X_{i} Y_{i}\right)}{\sum Y_{i}}
\end{gathered}
$$

To reduce our logic space, or the number of possible condition values, we made simplifying assumptions for each condition $[59,60]$. In this particular study, the expected theoretical direction of relationships between our conditions and outcomes was assumed to be positive-in other words the presence of a condition results in the presence of an outcome. For example, we would reasonably assume that the presence of coordination during planning would lead to resilience, not the absence of coordination. We then performed an initial screening of condition necessity scores for each outcome, assessing whether the outcome was a subset of a condition. None of the conditions displayed low necessity, defined as less than 0.3 , thus we included all six conditions in our final analysis for the outcomes of resilience, sustainability and the combination of the two. Details of the specific analysis procedures can be found in the Supplementary Information, S3.

\section{Findings}

We will discuss our findings for each outcome individually, and then conclude with a discussion of themes identified across the outcomes and projects. In the following sections, we present the solutions identified for each outcome in a diagram. An asterisk $(*)$ denotes the "and" Boolean operator. The absence of a condition is show by a tilde $(\sim)$ before a condition.

\subsection{Resilience}

To reiterate, we defined resilience as the capacities required to support community infrastructure system functionality after a disaster. Six of the identified nineteen projects showed the presence of resilience across all four dimensions considered (infrastructure, governance, economic, and social). We found two pathways, shown in Figure 3, that collectively had a solution consistency of 0.87 and a coverage of 0.48 . The identified pathways covered five of the six cases that exhibited resilience. The sixth case was close to falling into the first identified pathway; however, its participation during construction was ambiguous, with an assigned a score of 0.5 , narrowly excluding it. Case seventeen fell into both pathways, as all of its conditions across project phases had high degrees of membership. Both pathways included participation during planning and training during the construction phase of projects. These suggest that early decision-making combined with knowledge exchange during construction is a central process.

Coordination during planning had a high necessity value of 0.88 , although it appeared in only one of the two identified pathways to achieve resilience, offset by participation during construction. In all but one of the cases that exhibited resilience, projects included support for other sectors beyond just shelter, including WASH, livelihood, and DRR aspects, displaying strong coordination across different settlement dimensions. One NGO manager described the intent of this early integration, "The effect of Yolanda (Haiyan) gave us a picture that it is not only houses that are damaged; it is the people or the settlement. Therefore, during the preparation of the project, we ensured that the project will not only focus on building houses. It should be rebuilding back the settlement or the habitat where the community, and where the people are living". The importance of coordination during the later design stage also arose as important in one of the pathways where alignment with standards saw noticeable differences in the quality of constructed shelter and increased access to services, such as a latrines. 


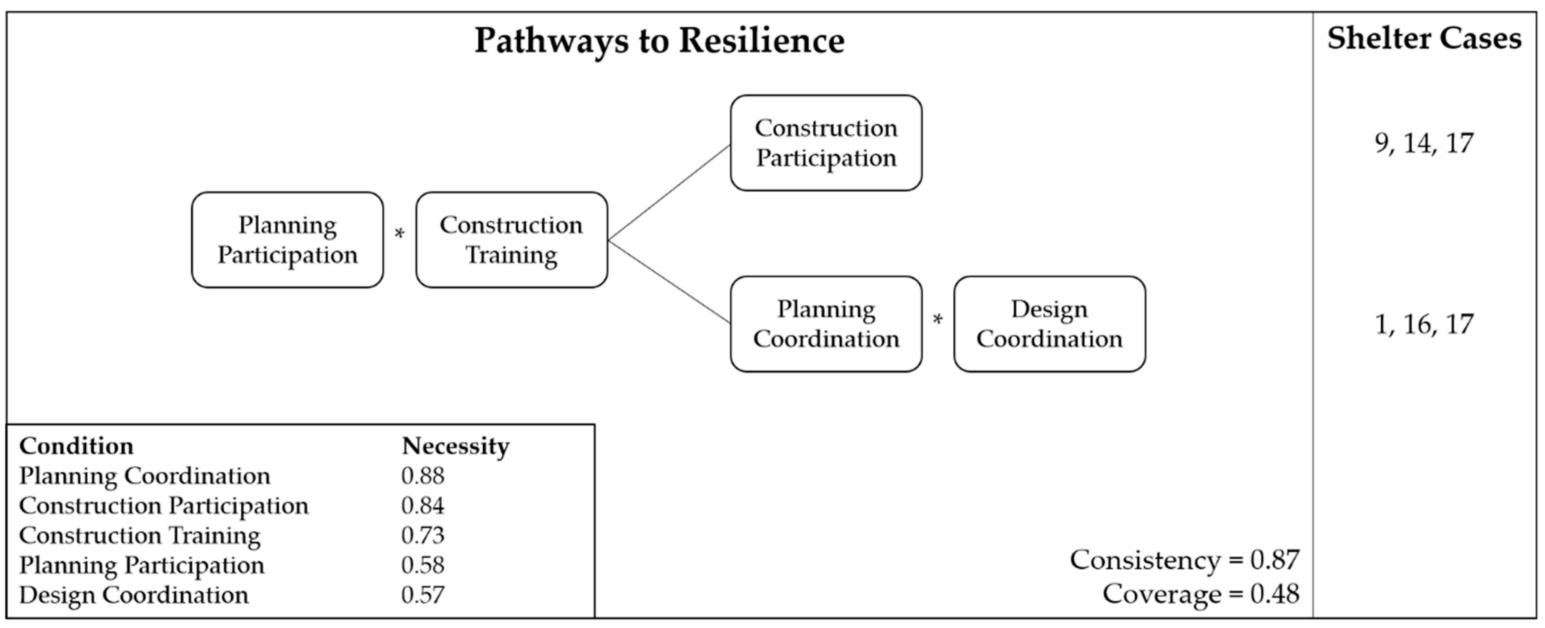

Figure 3. Resilience pathways.

In communities that did not achieve resilient infrastructure outcomes, there was a noticeable absence of early coordination, which lead us to validate the importance of this condition. For instance, in a shelter project that lacked coordination during planning, a beneficiary described the loss of water service after Typhoon Hagupit approximately a year after Haiyan, "Before they used to deliver water every Tuesday, Thursday, and Saturday, but lately after Typhoon Ruby (Hagupit), it has not taken place". In this case, the absence of coordination outside of shelter contributed the deterioration of water service delivery. While shelter activities were coordinated during planning for this project, other services were omitted from coordination because of the expected temporary nature of the project. Shelters were still being occupied over two years beyond their intended lifespan at the time of observation.

In addition to participation during planning and construction training, the first pathway also included participation during construction. Both projects that fell into this pathway provided in situ shelter assistance, allowing households to select the location where their shelter would be built. One of the projects used a conditional cash-transfer and the other provided materials. The organisations for these projects spent extensive time and resources involving households in needs assessments to determine aid provision. In addition, both projects provided training to household beneficiaries to supplement material or cash assistance with knowledge. This was particularly helpful in ensuring that resources were allocated toward more robust designs and construction techniques. Deconstructing the types of participation during construction for these programs further, household participation was centred on decisions, such as overseeing construction finances or verifying the quality of construction work completed. Neither project had sweat equity requirements, which were observed in the other projects studied, and thus the households relied on hired labour for construction.

In contrast to the first pathway, two of the projects that fell into the second pathway were built directly by the assisting organisation. Construction training within these communities was aimed at skilled workers, and in contrast to the first pathway, did not include households. Significant participation during planning was however found within this pathway, consisting of tailored household assessments and the ability to select the shelter location. The chief addition from this pathway; however, was coordination across both planning and design phases. These cases paralleled our discussion above of early participation; however, the noticeable trait of design coordination was adherence to uniform design standards. For two of the projects, standards developed by the Shelter Cluster were used to guide designs, while the third project relied on the National Structural Code of the Philippines.

In summary, we see that shelter projects that led to resilience had early participation, particularly in decision making, and trained either households or skilled labour during construction. One NGO staff member described the combination of these project conditions, "We don't do anything [directly], people will have to do it, we can facilitate and train them to do it. We aren't procuring anything-only if they 
lack and we can't mobilize locally, then we can assist to guide that process .... It is integrated so we aren't sectoral. We leave it up to the community to set their priorities. We can't define any outputs yet because that is defined as part of the process". In addition to early participation and training, either construction participation or consistent coordination across phases was required.

\subsection{Sustainability}

We broadly found that shelter projects supported infrastructure sustainability, or the ability to maintain infrastructure assets over time. The means through which projects achieved this outcome varied across cases. Ten of the nineteen project cases showed signs of high sustainability with five projects identified in two pathways to the outcome. For the five projects not included in the pathways identified, but still exhibiting the sustainability outcome, there was ambiguity in determining whether households participated during construction or the level of training. Furthermore, in the two pathways identified, one pathway included the absence of participation during construction while the second pathway included the presence of the same condition, highlighting how such participation can be both beneficial and detrimental to sustainability. Similar to the outcome of resilience, coordination during planning was found to be nearly necessary, or close to a necessary condition value of 0.9 , for sustainability, with a necessity value of 0.89 . Our solution had an overall consistency of 0.93 , with a coverage of 0.68 . A summary of pathways identified can be found below in Figure 4 .

Construction training was common to both pathways, the result of supporting household construction knowledge, local workforce skills, employment, and increased income. A project manager described the impact of training, "From the start we trained more contractors. I mean this way they get some sort of livelihood. But more than that, when the time comes, you know something similar, God forbid, they will know how to build back, because they have done it in their communities". In the first pathway, training targeted skilled labour, using multiple methods to train carpenters. Community members also received training in multiple formats at length. For example, one project incorporated a month-long program to educate households on safer building and maintenance of shelters.

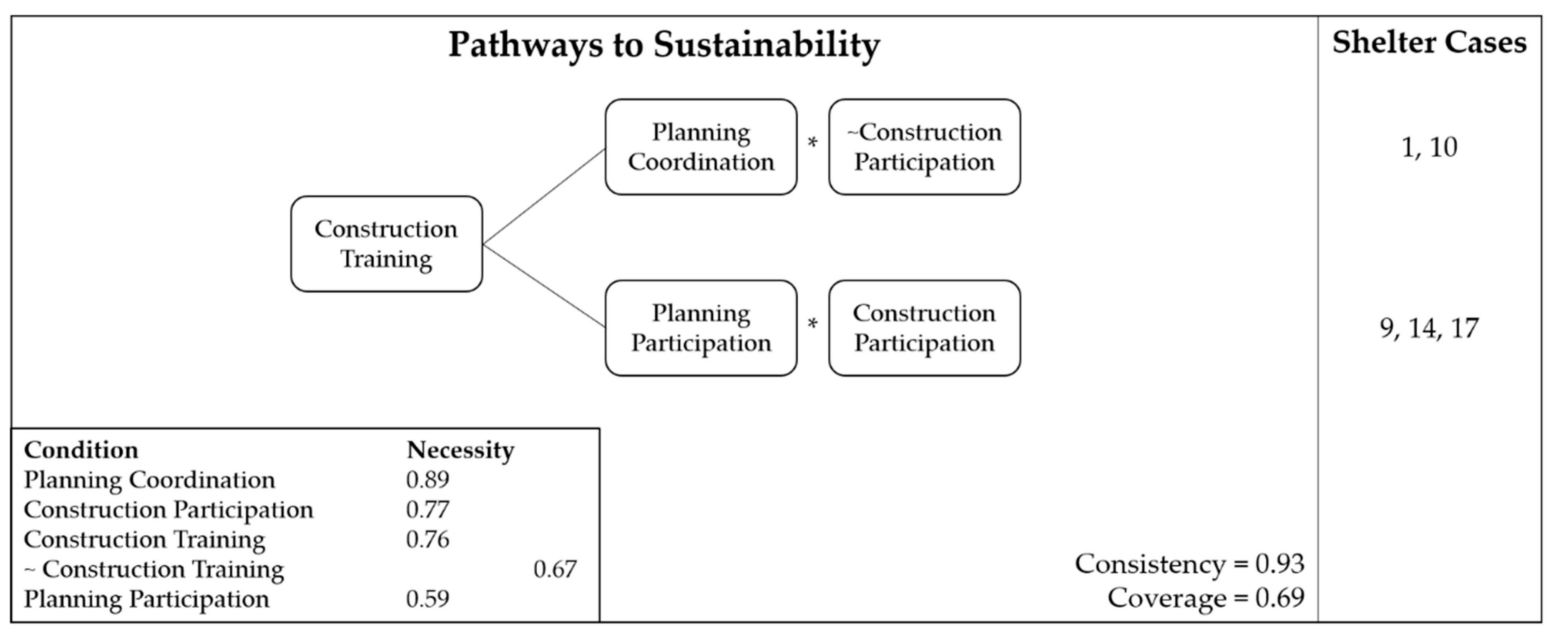

Figure 4. Sustainability pathways.

In addition to construction training, the first pathway also included coordination during planning and the absence of participation during construction. Both of the projects that fell into this pathway relied on directly building shelters for beneficiaries and were 'core shelters' intended to provide a secure dwelling that could be expanded in the future. Thus, this pathway represents a more directive, top-down model of assistance with little involvement from beneficiaries during the construction process. In addition, both projects also secured land tenure during early coordination; however, it is noteworthy that the second project in this pathway mandated 30 square meters of titled land in order to receive assistance, disqualifying many low-income households from receiving shelter assistance. 
Finally, the absence of participation during construction found in the first pathway can be attributed to the modality used to deliver shelter assistance-in this case, direct-build core shelters.

In contrast, the second pathway focused on a more bottom-up, inclusive approach, and thus included the presence of participation during construction and participation during planning in addition to construction training. Participation during the planning stages of projects resulted in modalities of assistance that closely tied with individual household objectives. For example, in one project, a majority of households were located on flood-prone land, but there was a strong desire to stay for social and economic reasons. Furthermore, while shelter was determined to be a priority, differing living arrangements were preferred, such as support for being hosted by a family member or retrofitting an existing structure. The shelter packages developed through this planning process catered to individual needs, leading to sustainable solutions by providing early choice. In contrast, projects that did not allow early participation of households in making these decisions, had significantly lower post-construction occupancy rates. For example, several projects mandated relocation to areas outside of the 'no-build zone', leading to occupancy rates frequently below 50 percent. Furthermore, early directives made by households during planning led to oversight of these directives by beneficiaries themselves during construction. Their early buy-in during planning helped lead to a desire to maintain control and direction during the later construction phase.

In comparing the two pathways, we can see that the first set of projects relied on simple and uniform shelter designs. As a result, the projects were completed significantly quicker, but afforded less customization, resulting in a basic one room structure which would be expanded upon. While this was a more direct approach, we found, as an early sign of success, that $89 \%$ of households in these projects had expanded on their shelters within a year of completion. This validates the capacity and ability of the households to maintain their shelter. For projects in the second pathway, the projects relied on 'owner-driven' or 'self-recovery' approaches. These modalities leveraged household-builder relationships and scoped planning to align with evolving recovery through training and participation during construction as well as early participation. Training for households allowed for more informed decisions in selecting builders and quality control of construction, which was overseen by the beneficiary.

\subsection{Combined Resilience and Sustainability}

In addition to assessing the individual outcomes of sustainability and resilience, we also explored pathways that led to the presence of both outcomes. The combined outcome pathways are shown in Figure 5.

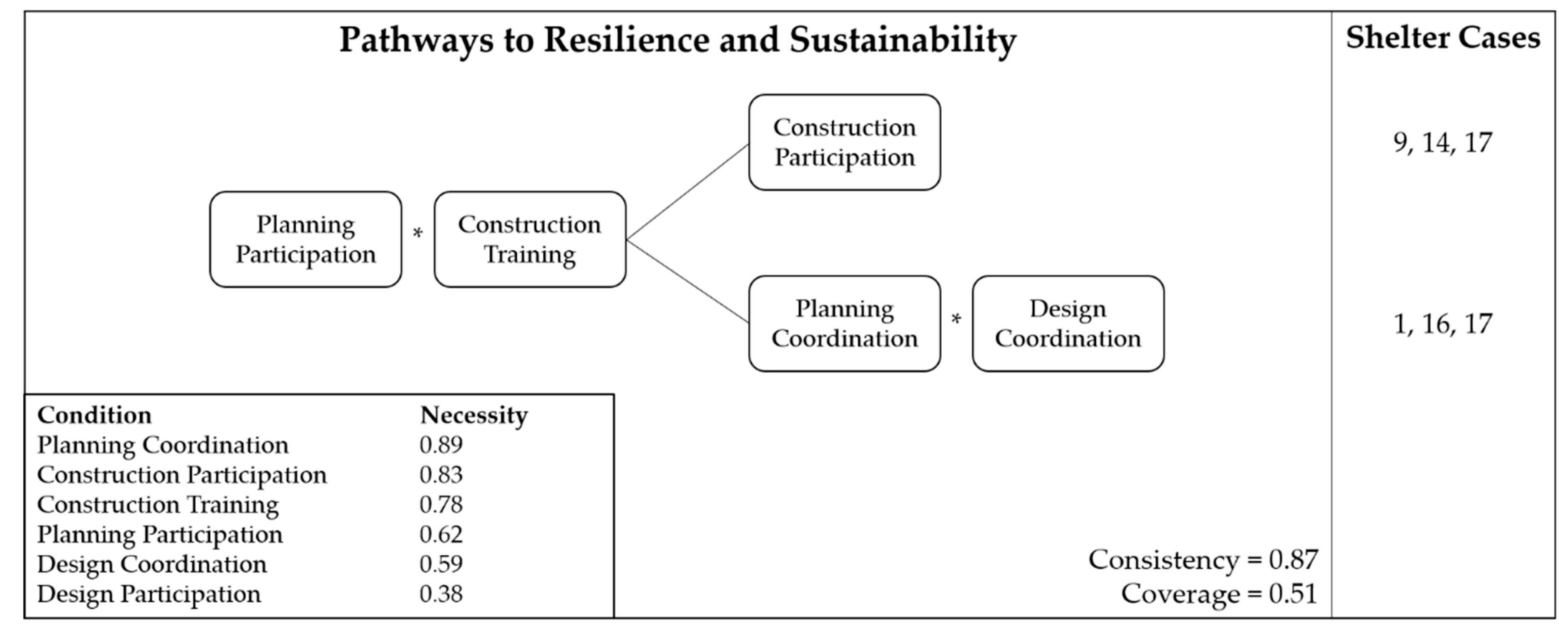

Figure 5. Combined resilience and sustainability pathways. 
Interestingly, we did not find any cases that exhibited resilience that did not also have high sustainability. As a result, when we analysed the pathways to combined resilient and sustainable infrastructure outcomes, the pathways were identical to the resilience pathways previously discussed. Thus, we found six cases that exhibited a combined outcome of resilience and sustainability; five of the cases were captured by the pathways displayed. Our solution consistency and coverage changed slightly and were 0.87 and 0.51 , respectively.

\section{Discussion}

There are several themes that surfaced across pathways to the individual and combined outcomes. In analysing unique outcomes, we found that more projects resulted in sustainable, rather than resilient, community infrastructure. Despite shortcomings in infrastructure resilience, all of the cases that showed the presence of resilience, also achieved sustainability. Broadly, we hypothesize that the higher number of cases exhibiting sustainability compared to resilience may be related to awareness in the humanitarian sector of these two outcomes; sustainability as a concept emerged in the 1980s while resilience has only recently come to the forefront of disaster practice. Additionally, many humanitarian organisations openly discussed that providing permanent solutions was not their intent and noted the difference in mandates between development and humanitarian sectors. Our analysis supports that this mindset often translated into programming, leading organisations to set up the building blocks for long-term recovery but neglected their potential role in transitioning to resilience building. Furthermore, the limited presence of resilient infrastructure suggests that there may be a minimum level of resources, either financial or social, required that exceeds those capacities needed for sustainability. For example, restoring pre-disaster livelihoods may yield income levels that are adequate to maintain the functionality of reconstructed infrastructure, yet these employment opportunities may be insufficient to allow for investment in risk reduction measures, such as more robust construction.

Of the relocation projects studied, none achieved either sustainable or resilient outcomes. Simply put, the upheaval of social and economic ties was detrimental to households. In several cases observed, households were required to spend over half their income on transportation back to economic centres for their livelihoods. Water, electricity, and sanitation services were also frequently absent or sub-standard quality, consistent with past research on relocation projects [61]. This distanciation of opportunities and services resulted in rapid degradation of infrastructure, with notable signs of disrepair occurring as quickly as one year after completion of shelters. However, the point in time at which our outcomes were assessed may explain the reason that none of the relocated communities had achieved the studied outcomes, as it is expected to take years before even basic services are completed on many of these sites. Despite potential for these sites to prosper in the future, past research and early indicators in this study suggest that such claims should be approached with caution.

As our pathways demonstrate, well-conceived project processes have the potential to positively impact infrastructure outcomes. Coordination, participation, and training at the right points in time offer the ability to align project goals with needs, support strong local economies, and improve living conditions. For our combined outcome, two conditions were critical-participation during planning and training during construction. The importance of early involvement of project stakeholders aligns with broader theory in housing assistance literature [62,63], suggesting that early decisions form a foundation on which later project tasks are formulated. We operationalized this participation through location selection and determination of aid. The former of these decisions suggests that is important to situate shelter project assistance within household settlement choice while the later points to aligning how this assistance is conceived.

Notably, a majority of projects continue to view programming as delivering shelter products, focusing on the number of beneficiaries assisted versus conceptualising shelter reconstruction as a process. Recognising the importance of participation and training, thinking of programming as a process requires organisations to think critically across project phases to determine key decision 
points that require community participation, and determining who should be trained on what topics. For instance, if organisations rely on a direct-build strategy, training of builders is critical for the initial product, but beneficiaries should also be trained for long-term ownership, recognising that many may adjust uniform direct-built shelter to suit their preferences. Thus, training should be focused on what future modifications can be made without jeopardizing the integrity of the shelter structure. Shifting thinking towards programming that embeds shelter within broader recovery strategy is not only needed, but imperative; the absence of such measures endanger making the humanitarian shelter sector irrelevant.

\section{Limitations}

The largest limitation of our study was that we focused specifically on shelter projects when seeking to explain differences in broader community infrastructure outcomes. Shelter assistance was only one part of assistance provided to many of the communities, and while we sought to control for, and capture, all assistance being provided to communities, we recognise there are other potential causal conditions missing from our analysis, such as the pre-disaster state of infrastructure. Despite this, the moderate to high coverage of our solutions suggests that we were able to explain most of the variation with our solutions. Furthermore, by spending extensive time in the field, we have attempted to mitigate extraneous variables that may have been needed to explain outcomes.

\section{Conclusions}

Foremost, we have identified post-disaster pathways to resilience and sustainability of infrastructure systems, answering calls to bring specificity to these outcomes [64-66]. Our adaptation of current resilience indicators from developed countries (e.g., [67]) and sustainability indicators from development contexts (e.g., [27]) provide a useful tool to replicate assessing both of these outcomes. We have opened the door to understanding the link between long-term operation and maintenance of infrastructure and the social, economic, and governance mechanisms that support functionality after disasters. Our findings further contribute to understanding of the modalities through which recovery efforts can be strengthened [68].

Our findings also further develop understanding of the project processes required to facilitate effective reconstruction after disasters. This work builds on previous efforts to connect management and disaster literatures [53], as well as further developing a theory of project governance in developing countries $[62,63]$. We do this by deconstructing three project processes-coordination, participation, and training-across project phases and assessing the impact of each, in isolation and combination, on resilience and sustainability outcomes.

We found that participation in planning and construction, combined with either training or coordination across phases, was influential for resilient and sustainable infrastructure outcomes. Theoretically, this points to the need to consider the interaction between project elements in achieving outcomes. For instance, training is often necessary for participation in construction processes-only attending to participation neglects the importance of knowledge transfer and skills needed for this participation to be effective. More broadly, organisations and governments should continue to focus on cross-sectoral programming that affords substantive participation of communities as a pathway to resilience while attending to capacity building skills that equip households to maintain reconstructed infrastructure to ensure sustainability.

Practically, our findings point to three main recommendations that include: (1) shifting from product delivery approaches to individual household recovery processes; (2) more fully integrating construction training and skills development into humanitarian shelter assistance; (3) identifying and supporting long-term linkages to recovery. In regard to the first recommendation, our findings point to the need to broaden what constitutes shelter programming. In place of envisioning shelter as 'four walls and a roof', practitioners must bring livelihoods, disaster risk reduction, and other sectors into proposed shelter activities. Rather than wait for broader reform in the humanitarian system, such as 
restructuring of the cluster system, organizations need to proactively seek out opportunities to bring beneficiary services together. Future research should seek to unpack mechanisms to integrate services in humanitarian programming, such as area-based and settlements-based approaches. Secondly, shelter projects must begin to consider the role of training and capacity building as central elements of assistance, rather than just peripheral elements. Less than half of the projects we studied had a formal educational component focused on safer building. There are continued gaps in understanding the mobilisation of knowledge in recovery-a critical area for future study.

Lastly, there is a need to align humanitarian shelter projects with long-term recovery objectives. In practice, this means ensuring linkages to long-term recovery from the start. For example, if transitional shelter is selected as a modality, it is imperative to identify the steps needed to ensure sufficient upgrading or transfer to permanent solutions. The large number of core shelter programs in this study that led to resilience and sustainability suggests there is a need for continued research on the links between incremental approaches and desired outcomes. Too often, the humanitarian shelter sector has hidden behind the veil of its mandate without consideration for repercussion of actions taken. Establishing a cohesive agenda for the humanitarian and development sectors should continue to emerge as priority at an institutional level [69].

Supplementary Materials: The following are available online at http://www.mdpi.com/2071-1050/10/11/ 4241/s1, S1: Condition and Outcome Calibration Descriptions; S2: Data Collection Instruments; S3: Qualtiative Comparative Analysis Procedures.

Author Contributions: Conceptualization, A.O., A.J.-W. and M.K.; Formal analysis, A.O. and A.J.-W.; Funding acquisition, A.O., A.J.-W. and M.K.; Investigation, A.O. and A.J.-W.; Methodology, A.O. and A.J.-W.; Project administration, A.O., A.J.-W. and M.K.; Supervision, A.O., A.J.-W. and M.K.; Validation, A.O. and A.J.-W.; Visualization, A.J.-W.; Writing—original draft, A.O. and A.J.-W.; Writing—review \& editing, A.O., A.J.-W. and M.K.

Funding: This material is based upon work supported by the National Science Foundation under Grant No. 1434791, the Nicolas R. and Nancy D. Petry Fellowship in Construction Engineering and Management, and the United States Agency for International Development Office for U.S. Foreign Disaster Assistance under Award No. AID-OFDA-G-16-00048. Any opinions, findings, and conclusions or recommendations expressed in this material are those of the author(s) and do not necessarily reflect the views the funding agencies.

Acknowledgments: We would like to thank Hannah Moench for assisting with the qualitative analysis and Marielle Bacason, Phoebe Tabo, Jairus Josol, and Lebeth Manguilimotan for their assistance in collecting the data.

Conflicts of Interest: The authors declare no conflict of interest. The funders had no role in the design of the study; in the collection, analyses, or interpretation of data; in the writing of the manuscript, or in the decision to publish the results.

\section{Appendix A}

Table A1. Planning condition calibrations.

\begin{tabular}{|c|c|}
\hline \multicolumn{2}{|c|}{ Coordination } \\
\hline \multicolumn{2}{|c|}{ Average of shelter sector involvement, cross-sector integration, and land rights } \\
\hline \multicolumn{2}{|r|}{ Shelter Sector Involvement } \\
\hline 0 & Shelter organisation was aware of cluster coordination but did not attend meetings or report activities. \\
\hline 0.33 & $\begin{array}{l}\text { Shelter organisation was aware of cluster coordination and attended sporadically but did not send } \\
\text { a consistent person to meetings and did not report activities. }\end{array}$ \\
\hline 0.67 & $\begin{array}{l}\text { Shelter organisation attended shelter cluster meetings but did not send a consistent person. } \\
\text { The organisation did report on activities to the cluster. }\end{array}$ \\
\hline 1 & $\begin{array}{l}\text { Shelter agency actively attended cluster meetings by sending a consistent person and reported activities } \\
\text { to the cluster. }\end{array}$ \\
\hline \multicolumn{2}{|c|}{ Cross-Sector Integration } \\
\hline \multicolumn{2}{|c|}{ Sum of scores for each sector included in shelter programming: } \\
\hline 0.33 & Livelihood \\
\hline 0.33 & WASH \\
\hline 0.33 & Disaster Risk Reduction \\
\hline
\end{tabular}


Table A1. Cont.

\begin{tabular}{|c|c|}
\hline \multicolumn{2}{|c|}{ Coordination } \\
\hline \multicolumn{2}{|r|}{ Land Rights } \\
\hline 0 & Land tenure was not secured for the duration of the shelter assistance provided. \\
\hline 0.7 & Tenure secured, but no documentation provided to beneficiary. \\
\hline 1 & Land tenure was secured in advance of construction. \\
\hline \multicolumn{2}{|c|}{ Stakeholder Participation } \\
\hline \multicolumn{2}{|c|}{ Average of location selection and determination of aid } \\
\hline \multicolumn{2}{|r|}{ Location Selection } \\
\hline 0 & Households had no say in location of shelter-government or NGO determined relocation. \\
\hline 1 & Households made decision of location of shelter. \\
\hline \multicolumn{2}{|r|}{ Determination of Aid } \\
\hline 0 & $\begin{array}{l}\text { Donor funding or organisation pre-determined type of aid and requirements. Households were not } \\
\text { involved in assessing needs. }\end{array}$ \\
\hline 0.7 & $\begin{array}{l}\text { Implementing organisation determined type of aid based on second-hand assessment (NGO or } \\
\text { government conducted) without consultation with households. }\end{array}$ \\
\hline 1 & $\begin{array}{l}\text { Implementing organisation determined type of aid based on first-hand assessment (NGO or } \\
\text { government conducted) with consultation with households. }\end{array}$ \\
\hline
\end{tabular}

Table A2. Design condition calibrations.

\begin{tabular}{|c|c|}
\hline \multicolumn{2}{|c|}{ Coordination } \\
\hline \multicolumn{2}{|c|}{ Average of provision of WASH and uniform design standards } \\
\hline \multicolumn{2}{|r|}{ Provision of WASH } \\
\hline 0 & Water supply and sanitation facilities were not included in housing design. \\
\hline 0.33 & Water supply OR sanitation facilities were provided in housing design. \\
\hline 0.67 & Design included access to water supply AND shared sanitation facilities. \\
\hline 1 & Design included access to water supply AND private sanitation facilities. \\
\hline \multicolumn{2}{|r|}{ Uniform Design Standards } \\
\hline 0 & Few, if any, Shelter Cluster messages were considered in the design of shelter. \\
\hline 0.33 & $\begin{array}{l}\text { Minor adaptations were included in shelter design, but significant recommendations outlined in Shelter } \\
\text { Cluster guidance were omitted. }\end{array}$ \\
\hline 0.67 & $\begin{array}{l}\text { Major design elements recommended by the Shelter Cluster, such as bracing, were included in the } \\
\text { design of shelter. }\end{array}$ \\
\hline 1 & Household or organisation developed design in-line with all Shelter Cluster messaging. \\
\hline \multicolumn{2}{|r|}{ Stakeholder Participation } \\
\hline \multicolumn{2}{|c|}{ Average of floorplan and layout and government permitting } \\
\hline \multicolumn{2}{|r|}{ Floorplan and Layout } \\
\hline 0 & Households were never consulted on the floorplan and layout of the shelter. \\
\hline 0.33 & Households were consulted through a large community meeting to discuss housing features. \\
\hline 0.67 & $\begin{array}{l}\text { Households were provided floor plan and asked preferences, such as location of doors and windows, } \\
\text { that were then included in the final design. }\end{array}$ \\
\hline 1 & $\begin{array}{l}\text { Households were asked to actively participate in the development of floorplans and had control over } \\
\text { final design decisions. }\end{array}$ \\
\hline \multicolumn{2}{|r|}{ Government Permitting } \\
\hline 0 & Municipal government did not provide documented permission on design of shelter. \\
\hline 1 & $\begin{array}{l}\text { Municipal government was consulted prior to construction, provided recommendations and } \\
\text { written approval. }\end{array}$ \\
\hline
\end{tabular}


Table A3. Construction condition calibrations.

\begin{tabular}{|c|c|}
\hline \multicolumn{2}{|c|}{ Stakeholder Participation } \\
\hline \multicolumn{2}{|r|}{ Average of sweat equity, material procurement, financial management, and oversight } \\
\hline \multicolumn{2}{|c|}{ Sweat Equity } \\
\hline 0 & Household was not involved in construction labour. \\
\hline 0.33 & $\begin{array}{l}\text { Household contributed minimal labour during construction. Tasks were confined to site works, } \\
\text { not construction. }\end{array}$ \\
\hline 0.67 & $\begin{array}{l}\text { Homeowner contributed minimal labour to construction. Tasks involved construction, not just } \\
\text { site work. }\end{array}$ \\
\hline 1 & $\begin{array}{l}\text { Homeowner contributed significant labour to construction. Tasks may have involved a combination of } \\
\text { construction and site work. }\end{array}$ \\
\hline \multicolumn{2}{|r|}{ Material Procurement } \\
\hline 0 & Homeowner was not involved in the material procurement process. \\
\hline 1 & $\begin{array}{l}\text { Homeowner was required to receive, inspect, and certify materials from organisation, provide } \\
\text { protection during construction, and organize transportation, if required. }\end{array}$ \\
\hline \multicolumn{2}{|r|}{ Financial Management } \\
\hline 0 & Beneficiary was not responsible for any aspect of managing shelter construction finances. \\
\hline 0.7 & $\begin{array}{l}\text { Beneficiary was responsible for managing labour expenses for shelter construction or a component of } \\
\text { material expenses. }\end{array}$ \\
\hline 1 & Beneficiary had significant role in managing shelter budget including labour and materials. \\
\hline \multicolumn{2}{|c|}{ Oversight } \\
\hline 0 & No inspection of construction. \\
\hline 0.3 & $\begin{array}{l}\text { Organisation and household members inspected shelter at sporadic milestones; however no action was } \\
\text { observed on items requiring rework or modification. }\end{array}$ \\
\hline 1 & $\begin{array}{l}\text { Organisation and household members inspected shelter at major milestones. Action was observed on } \\
\text { items that required rework or modification. }\end{array}$ \\
\hline \multicolumn{2}{|c|}{ Training } \\
\hline \multicolumn{2}{|c|}{ Minimum of observations and diversity of methods } \\
\hline \multicolumn{2}{|c|}{ Observations } \\
\hline 0 & Household was NOT present during shelter construction. \\
\hline 1 & Household was present during shelter construction. \\
\hline \multicolumn{2}{|c|}{ Diversity of Methods } \\
\hline 0 & No training was provided to homeowners. \\
\hline 0.33 & Training methods used 2 of the 4 experiential learning theory poles. \\
\hline 0.67 & Training methods used 3 of the 4 experiential learning theory poles. \\
\hline 1 & Training methods were used that covered all four poles of the Kolb Learning Style Inventory. \\
\hline
\end{tabular}

Table A4. Resilience outcome calibrations.

\begin{tabular}{|c|c|}
\hline \multicolumn{2}{|c|}{ Infrastructure } \\
\hline \multicolumn{2}{|r|}{$\begin{array}{l}\text { Average of housing, water access, sanitation access, electrical access, education access, medical care access, } \\
\text { transportation, and evacuation centres }\end{array}$} \\
\hline \multicolumn{2}{|c|}{ Housing: minimum of housing design and housing construction quality } \\
\hline \multicolumn{2}{|r|}{ Housing Design } \\
\hline \multicolumn{2}{|r|}{ Directly calibrated based on average number of Shelter Cluster "8 Key Messages" observed. } \\
\hline 0.05 & Average of 3 "Key Messages" present in design \\
\hline & Average of 5 "Key Messages" present in design \\
\hline 1 & Average of 7 "Key Messages" present in design \\
\hline \multicolumn{2}{|r|}{ Housing Construction Quality } \\
\hline 0 & $\begin{array}{l}\text { Houses are constructed using sub-standard materials and there are significant defects in the } \\
\text { construction. }\end{array}$ \\
\hline 0.33 & Housing units use quality materials, but significant defects are present in the construction. \\
\hline 0.67 & Housing units use standard materials, but no defects are present in construction \\
\hline 1 & High quality materials are used and no defects are found in construction. \\
\hline
\end{tabular}


Table A4. Cont.

\begin{tabular}{|c|c|}
\hline \multicolumn{2}{|c|}{ Infrastructure } \\
\hline \multicolumn{2}{|r|}{ Water Access } \\
\hline 0 & Water source is over $10 \mathrm{~min}$ walking distance and quantity provided is less than 15 liters/person/day. \\
\hline 0.33 & Water source is under $10 \mathrm{~min}$ walking distance, but quantity provided is less than 15 liters/person/day. \\
\hline 0.67 & Water source is over $10 \mathrm{~min}$ walking distance, but quantity provided is 15 liters/person/day or more. \\
\hline 1 & Water source is within $10 \mathrm{~min}$ walking distance and quantity provided is 15 liters/person/day or more. \\
\hline \multicolumn{2}{|c|}{ Sanitation Access } \\
\hline 0 & Open defecation is predominant sanitation practice \\
\hline 0.3 & More than $25 \%$ of households share communal or neighbor's toilets \\
\hline 1 & Households have private access to a toilet \\
\hline \multicolumn{2}{|c|}{ Electrical Access } \\
\hline 0 & Households have no access to electrical connection \\
\hline 0.7 & Households predominantly share a power connection with a neighbour or collective of neighbours. \\
\hline 1 & Households have private electrical connections \\
\hline \multicolumn{2}{|c|}{ Education Access } \\
\hline 0 & Nearest primary and high school is more than $30 \mathrm{~min}$ \\
\hline 0.33 & Nearest primary and high school is between $15 \mathrm{~min}$ to $30 \mathrm{~min}$. \\
\hline 0.67 & Nearest primary and high school is between $5 \mathrm{~min}$ and $15 \mathrm{~min}$. \\
\hline 1 & Nearest primary and high school is less than $5 \mathrm{~min}$. \\
\hline \multicolumn{2}{|c|}{ Medical Care Access } \\
\hline 0 & Nearest hospital is more than $1 \mathrm{~h}$. \\
\hline 0.33 & Nearest hospital is between $30 \mathrm{~min}$ to $1 \mathrm{~h}$. \\
\hline 0.67 & Nearest hospital is between $15 \mathrm{~min}$ and $30 \mathrm{~min}$. \\
\hline 1 & Nearest hospital is less than $15 \mathrm{~min}$. \\
\hline \multicolumn{2}{|r|}{ Transportation } \\
\hline 0 & Barangay roads are of poor quality and are either dirt or show significant signs of cracking. \\
\hline 0.33 & $\begin{array}{l}\text { Barangay roads are of below average quality and are a mix of dirt and/or paved, with minor signs of } \\
\text { cracking or rutting. }\end{array}$ \\
\hline 0.67 & $\begin{array}{l}\text { Barangay roads are of above average quality and are a mix of dirt and/or paved, with no signs of } \\
\text { cracking or rutting. }\end{array}$ \\
\hline 1 & Barangay roads are of excellent quality and are all paved with minimal sizes of cracking or rutting. \\
\hline \multicolumn{2}{|r|}{ Evacuation Centres } \\
\hline 0 & Distance to nearest safe evacuation site is more than $500 \mathrm{~m}$. \\
\hline 1 & Distance to nearest safe evacuation site is less than $500 \mathrm{~m}$. \\
\hline \multicolumn{2}{|c|}{ Governance } \\
\hline \multicolumn{2}{|c|}{ Average of disaster management planning and regional cooperation } \\
\hline \multicolumn{2}{|c|}{ Disaster Management Planning } \\
\hline 0 & Barangay has not held any evacuation drills in the last year. \\
\hline 0.7 & $\begin{array}{l}\text { Barangay has held evacuation drill in the last year with assistance from municipal government or } \\
\text { non-governmental organisation. }\end{array}$ \\
\hline 1 & $\begin{array}{l}\text { Barangay has initiated its own evacuation drill in the last year without assistance from external } \\
\text { organisation. }\end{array}$ \\
\hline \multicolumn{2}{|r|}{ Regional Cooperation } \\
\hline 0 & $\begin{array}{l}\text { Low cooperation between neighbouring barangays and municipality and the barangay has NOT shared } \\
\text { its disaster management plan with neighbouring barangays and its municipality. }\end{array}$ \\
\hline 0.33 & $\begin{array}{l}\text { Low cooperation between neighbouring barangays and municipality but the barangay has shared its } \\
\text { disaster management plan with neighbouring barangays and its municipality. }\end{array}$ \\
\hline 0.67 & $\begin{array}{l}\text { Strong cooperation between neighbouring barangays and municipality but the barangay's disaster } \\
\text { management plans have NOT been shared with neighbouring barangays and its municipality. }\end{array}$ \\
\hline 1 & $\begin{array}{l}\text { Strong cooperation between neighbouring barangays and municipality and barangay has shared its } \\
\text { disaster management plan with neighbouring barangays and municipality. }\end{array}$ \\
\hline
\end{tabular}


Table A4. Cont.

\begin{tabular}{|c|c|}
\hline \multicolumn{2}{|c|}{ Economic } \\
\hline \multicolumn{2}{|c|}{ Average of household savings and employment } \\
\hline \multicolumn{2}{|c|}{ Household Savings } \\
\hline \multicolumn{2}{|c|}{ Directly calibrated based on average housing savings } \\
\hline 0.05 & P0 \\
\hline 0.5 & P317 (1 day of savings at poverty threshold) \\
\hline 0.95 & P1582 (5 days of savings at poverty threshold) \\
\hline \multicolumn{2}{|c|}{ Employment } \\
\hline \multicolumn{2}{|c|}{ Directly calibrated-based labour force participation rate. } \\
\hline 0.05 & $50 \%$ labour participation \\
\hline 0.5 & 64.3\% labour participation (2016 average for Region VIII in Philippines) \\
\hline 0.95 & $75 \%$ labour participation \\
\hline \multicolumn{2}{|l|}{ Social } \\
\hline \multicolumn{2}{|r|}{ Average of social capital, native to community, and community organisations and mobilization } \\
\hline \multicolumn{2}{|r|}{ Social Capital } \\
\hline 0 & Households inform their neighbours of meeting and opportunities. \\
\hline 0.33 & Households provide food to those households in need. All previous aspects are also present. \\
\hline 0.67 & $\begin{array}{l}\text { Community members provide non-reimbursed cash to neighbours in need. All previous aspects are } \\
\text { also present. }\end{array}$ \\
\hline 1 & $\begin{array}{l}\text { Households provide medical care to neighbours in addition to other time intensive activities such as } \\
\text { child care. All previous aspects are also present. }\end{array}$ \\
\hline \multicolumn{2}{|r|}{ Native to Community } \\
\hline 0 & Household heads are born in other province than currently residing. \\
\hline 0.33 & Household heads are born in province of current residence. \\
\hline 0.67 & Household heads are born in municipality of current residence. \\
\hline 1 & Household heads are born in barangay of current residence. \\
\hline \multicolumn{2}{|r|}{ Community Organisations and Mobilization } \\
\hline 0 & $\begin{array}{l}\text { Households do not participate in barangay meetings (if held) and there are not informal social groups } \\
\text { within barangay. }\end{array}$ \\
\hline 0.33 & Households actively attend barangay meetings on a regular basis. \\
\hline 0.67 & Presence of informal groups, such as around livelihood activities or a homeowners association. \\
\hline 1 & $\begin{array}{l}\text { Formalized groups present, such as the Red Cross or local NGOs, with active participation with } \\
\text { barangay households. }\end{array}$ \\
\hline
\end{tabular}

Table A5. Sustainability outcome calibrations.

\begin{tabular}{|c|c|}
\hline \multicolumn{2}{|c|}{ Economic } \\
\hline \multicolumn{2}{|c|}{ Average of household wealth and service interruptions } \\
\hline \multicolumn{2}{|c|}{ Household Wealth } \\
\hline \multicolumn{2}{|c|}{ Directly calibrated based on per capita household weekly income } \\
\hline 0.05 & P316 per capita per week \\
\hline 0.5 & P353 per capita per week \\
\hline 0.95 & P444 per capita per week \\
\hline \multicolumn{2}{|c|}{ Service Interruptions } \\
\hline 0 & Service interruptions to water and/or electricity are once per day. \\
\hline 0.33 & Service interruptions to water and/or electricity are once per week. \\
\hline 0.67 & Service interruptions to water and/or electricity are once per month. \\
\hline 1 & Service interruptions to water and/or electricity are infrequently or never. \\
\hline \multicolumn{2}{|l|}{ Social } \\
\hline \multicolumn{2}{|c|}{ Average of land tenure and shelter satisfaction } \\
\hline \multicolumn{2}{|c|}{ Land Tenure } \\
\hline 0 & Informal settlement \\
\hline 0.2 & Rent (free) \\
\hline 0.6 & Rent (paid) \\
\hline 0.8 & Own (w/o land title) \\
\hline 1 & Own (w/land title) \\
\hline
\end{tabular}


Table A5. Cont.

\begin{tabular}{ll}
\hline Social & \\
\hline Shelter & Satisfaction \\
Directly & calibrated based on household satisfaction survey results ( -1 to 1$)$ \\
0.05 & 0 weighted satisfaction average ("about the same as pre-disaster shelter") \\
0.5 & 0.25 weighted satisfaction average \\
0.95 & 0.5 weighted satisfaction average ("somewhat better than pre-disaster shelter") \\
\hline Environmental \\
\hline Average of sanitation system and building material sourcing \\
\hline Sanitation & System \\
0 & Open defecation \\
0.33 & Unlined pit latrine \\
0.67 & Lined pit latrine \\
1 & Septic tank \\
\hline Building & Material Sourcing \\
0 & Building material and components are not available locally. \\
0.33 & Some, but not all, building materials are available locally. \\
0.67 & All of the building materials are available locally, except for specialty items. \\
1 & All building materials and components are available locally. \\
\hline
\end{tabular}

\section{References}

1. Guha-Sapir, D.; Hoyois, P.; Below, R. Annual Disaster Statistical Review 2015; Centre for Research on the Epidemiology of Disasters (CRED), Institute of Health and Society (IRSS), Universite Catholique de Louvain: Brussels, Belgium, 2015.

2. Parker, R.S. Hazards of Nature, Risks to Development: An IEG Evaluation of World Bank Assistance for Natural Disasters; The World Bank: Washington, DC, USA, 2006; ISBN 978-0-8213-6650-9.

3. Fisher, D.; Hagon, K.; Lattimer, C.; O'Callaghan, S.; Swithern, S.; Walmsley, L. World Disasters Report 2018 : Leaving No One Behind; Fisher, D., Swithern, S., Walmsley, L., Eds.; International Federation of Red Cross and Red Crescent Societies: Geneva, Switzerland, 2018; ISBN 978-2-9701289-0-8.

4. Quarantelli, E.L. General and particular observations on sheltering and housing in American disasters. Disasters 1982, 6, 277-281. [CrossRef]

5. Quarantelli, E.L. Patterns of sheltering and housing in US disasters. Disaster Prev. Manag. Int. J. 1995, 4, 43-53. [CrossRef]

6. Mileti, D. Disasters by Design: A Reassessment of Natural Hazards in the United States; Joseph Henry Press: Washington, DC, USA, 1999; ISBN 978-0-309-13266-4.

7. Davis, I. Shelter after Disaster, 2nd ed.; Davis, I., Thompson, P., Krimgold, F., Eds.; International Federation of Red Cross and Red Crescent Societies and the United Nations Office for the Coordination of Humanitarian Affairs: Lyons, France, 2015.

8. Blackman, D.; Nakanishi, H.; Benson, A.M. Disaster resilience as a complex problem: Why linearity is not applicable for long-term recovery. Technol. Forecast. Soc. Chang. 2017, 121, 89-98. [CrossRef]

9. Lloyd-Jones, T. Mind the Gap! Post-Disaster Reconstruction and the Transition from Humanitarian Relief; Royal Institution of Chartered Surveyors: London, UK, 2006.

10. Drabek, T.E. Community processes: Coordination. In Handbook of Disaster Research; Rodriguez, H., Quarantelli, E., Dynes, R., Eds.; Springer: New York, NY, USA, 2007; pp. 217-233.

11. Ritchie, L.A.; Tierney, K. Temporary housing planning and early implementation in the 12 January 2010 Haiti Earthquake. Earthq. Spectra 2011, 27, S487-S507. [CrossRef]

12. Barenstein, J.D. Who governs reconstruction? Changes and continuity in policies, practices and outcomes. In Rebuilding after Disasters: From Emergency to Sustainability; Lizarralde, G., Johnson, C., Davidson, C., Eds.; Routledge: New York, NY, USA, 2009; pp. 149-176. ISBN 978-1-134-02846-7.

13. Davidson, C.H.; Johnson, C.; Lizarralde, G.; Dikmen, N.; Sliwinski, A. Truth and myths about community participation in post-disaster housing projects. Habitat Int. 2007, 31, 100-115. [CrossRef]

14. Amaratunga, D.; Haigh, R. Post-Disaster Reconstruction of the Built Environment: Rebuilding for Resilience; John Wiley \& Sons: Chichester, UK, 2011; ISBN 978-1-4443-4492-9. 
15. Jordan, E.; Javernick-Will, A. Pathways to livelihood recovery: A study of tsunami-affected communities in Tamil Nadu, India. In Disasters' Impact on Livelihood and Cultural Survival: Losses, Opportunities, and Mitigation; Companion, M., Ed.; CRC Press: Boca Raton, FL, USA, 2015; pp. 167-181. ISBN 978-1-4822-4843-2.

16. Stephenson, M., Jr. Making humanitarian relief networks more effective: Operational coordination, trust and sense making. Disasters 2005, 29, 337-350. [CrossRef] [PubMed]

17. Völz, C. Humanitarian coordination in Indonesia: An NGO viewpoint. Forced Migr. Rev. 2005, Special Issue, 26-27.

18. Van der Vegt, G.S.; Essens, P.; Wahlström, M.; George, G. Managing risk and resilience. Acad. Manag. J. 2015, 58, 971-980. [CrossRef]

19. Lizarralde, G.; Massyn, M. Unexpected negative outcomes of community participation in low-cost housing projects in South Africa. Habitat Int. 2008, 32, 1-14. [CrossRef]

20. Opdyke, A.; Javernick-Will, A.; Koschmann, M. Assessing the impact of household participation on satisfaction and safe design in humanitarian shelter projects. Disasters. in press.

21. Jordan, E.; Javernick-Will, A.; Amadei, B. Post-disaster reconstruction: Lessons from Nagapattinam district, India. Dev. Pract. 2015, 25, 518-534. [CrossRef]

22. Jordan, E.; Javernick-Will, A.; Tierney, K. Post-tsunami recovery in Tamil Nadu, India: Combined social and infrastructural outcomes. Nat. Hazards 2016, 84, 1327-1347. [CrossRef]

23. Ginige, K.; Amaratunga, D. Capacity development for post-disaster reconstruction of the built environment. In Post-Disaster Reconstruction of the Built Environment: Rebuilding for Resilience; Amaratunga, D., Haigh, R., Eds.; John Wiley \& Sons: Chichester, UK, 2011; pp. 13-29. ISBN 978-1-4443-4492-9.

24. Maynard, V.; Parker, E.; Twigg, J. The Effectiveness and Efficiency of Interventions Supporting Shelter Self-Recovery Following Humanitarian Crises: An Evidence Synthesis; Humanitarian Evidence Programme: Oxford, UK, 2017.

25. Norris, F.H.; Stevens, S.P.; Pfefferbaum, B.; Wyche, K.F.; Pfefferbaum, R.L. Community Resilience as a metaphor, theory, set of capacities, and strategy for disaster readiness. Am. J. Community Psychol. 2008, 41, 127-150. [CrossRef] [PubMed]

26. Opdyke, A.; Javernick-Will, A.; Koschmann, M. Infrastructure hazard resilience trends: An analysis of 25 years of research. Nat. Hazards 2017, 87, 773-789. [CrossRef]

27. Ugwu, O.O.; Haupt, T.C. Key performance indicators and assessment methods for infrastructure sustainability-A South African construction industry perspective. Build. Environ. 2007, 42, 665-680. [CrossRef]

28. Pantuliano, S. (Ed.) Uncharted Territory: Land, Conflict and Humanitarian Action; Practical Action Publishing: Rugby, UK, 2009; ISBN 978-1-85339-687-8.

29. Snarr, D.N.; Brown, E.L. User Satisfaction with Permanent Post-Disaster Housing: Two Years after Hurricane Fifi in Honduras. Disasters 1980, 4, 83-91. [CrossRef] [PubMed]

30. Rand, E.C.; Hirano, S.; Kelman, I. Post-tsunami housing resident satisfaction in Aceh. Int. Dev. Plan. Rev. 2011, 33, 187-211. [CrossRef]

31. Shen, L.-Y.; Jorge Ochoa, J.; Shah, M.N.; Zhang, X. The application of urban sustainability indicators-A comparison between various practices. Habitat Int. 2011, 35, 17-29. [CrossRef]

32. Chen, R.; Sharman, R.; Rao, R. Coordination in emergency response management. Commun. ACM 2008, 51, 66-73. [CrossRef]

33. Office of the United Nations Disaster Relief Coordinator. Shelter After Disaster: Guidelines for Assistance; Office of the United Nations Disaster Relief Coordinator: New York, NY, USA, 1982.

34. Arnstein, S. A ladder of citizen participation. J. Am. Plann. Assoc. 1969, 35, 216-224. [CrossRef]

35. Choguill, M.B.G. A ladder of community participation for underdeveloped countries. Habitat Int. 1996, 20, 431-444. [CrossRef]

36. Oakley, P. The concept of participation in development. Landsc. Urban Plan. 1991, 20, 115-122. [CrossRef]

37. Hayward, C.; Simpson, L.; Wood, L. Still left out in the cold: Problematising participatory research and development. Sociol. Rural. 2004, 44, 95-108. [CrossRef]

38. Mohanty, R. Institutional dynamics and participatory spaces: The making and unmaking of participation in local forest management in India. Inst. Dev. Stud. Bull. 2004, 35, 26-32. [CrossRef]

39. Williams, G. Evaluating participatory development: Tyranny, power and (re)politicisation. Third World Q. 2004, 25, 557-578. [CrossRef] 
40. Chang, Y.; Wilkinson, S.; Potangaroa, R.; Seville, E. Donor-driven resource procurement for post-disaster reconstruction: Constraints and actions. Habitat Int. 2011, 35, 199-205. [CrossRef]

41. Mosse, D. People's knowledge, participation and patronage: Operations and representations in rural development. In Participation: The New Tyranny? Zed Books: London, UK, 2001; pp. 384-393.

42. Jordan, E.; Javernick-Will, A. Determining causal factors of community recovery. Int. J. Mass Emerg. Disasters 2014, 32, 405-427.

43. Binder, M. Paths to intervention: What explains the UN's selective response to humanitarian crises? J. Peace Res. 2015, 52, 712-726. [CrossRef]

44. Marín, A.; Bodin, Ö.; Gelcich, S.; Crona, B. Social capital in post-disaster recovery trajectories: Insights from a longitudinal study of tsunami-impacted small-scale fisher organizations in Chile. Glob. Environ. Chang. 2015, 35, 450-462. [CrossRef]

45. Ragin, C. The Comparative Method: Moving Beyond Qualitative and Quantitative Strategies; University of California Press: Berkeley, CA, USA, 1987; ISBN 978-0-520-90924-3.

46. Shelter Cluster Philippines. Final Analysis of Shelter Recovery; Shelter Cluster: Geneva, Switzerland, 2014.

47. Evans, A. Annual Tropical Cyclone Report 2013; Joint Typhoon Warning Center: Pearl Harbor, HI, USA, 2014.

48. Perante, W. 3 in Every 10 Families in Eastern Visayas are Poor; Philippines Statistics Authority: Quezon City, Philippines, 2016.

49. Flyvbjerg, B. Five misunderstandings about case-study research. Qual. Inq. 2006, 12, 219-245. [CrossRef]

50. Eisenhardt, K.M.; Graebner, M.E. Theory building from cases: Opportunities and challenges. Acad. Manag. J. 2007, 50, 25-32. [CrossRef]

51. Creswell, J.W.; Poth, C.N. Qualitative Inquiry and Research Design: Choosing among Five Approaches; SAGE Publications: Thousand Oaks, CA, USA, 2017; ISBN 978-1-5063-3019-8.

52. Stake, R.E. The Art of Case Study Research; SAGE Publications: Thousand Oaks, CA, USA, 1995; ISBN 978-0-8039-5767-1.

53. Johnson, C.; Lizarralde, G.; Davidson, C.H. A systems view of temporary housing projects in post-disaster reconstruction. Constr. Manag. Econ. 2006, 24, 367-378. [CrossRef]

54. Campbell, J.L.; Quincy, C.; Osserman, J.; Pedersen, O.K. Coding In-depth semistructured interviews: Problems of unitization and intercoder reliability and agreement. Sociol. Methods Res. 2013, 42, $294-320$. [CrossRef]

55. Landis, J.R.; Koch, G.G. The measurement of observer agreement for categorical data. Biometrics 1977, 33, 159-174. [CrossRef] [PubMed]

56. Basurto, X.; Speer, J. Structuring the calibration of qualitative data as sets for qualitative comparative analysis (QCA). Field Methods 2012, 24, 155-174. [CrossRef]

57. Ragin, C. The limitations of net-effects thinking. In Innovative Comparative Methods for Policy Analysis; Springer: New York, NY, USA, 2006; pp. 13-41.

58. Rihoux, B.; Ragin, C.C. Configurational Comparative Methods: Qualitative Comparative Analysis (QCA) and Related Techniques; SAGE Publications: Thousand Oaks, CA, USA, 2009; ISBN 978-1-4129-4235-5.

59. Ragin, C.; Sonnett, J. Between complexity and parsimony: Limited diversity, counterfactual cases, and comparative analysis. In Vergleichen in der Politikwissenschaft; Kropp, S., Minkenberg, M., Eds.; VS Verlag für Sozialwissenschaften: Wiesbaden, Germany, 2005; pp. 180-197. ISBN 978-3-322-80441-9.

60. Kaminsky, J.; Jordan, E. Qualitative comparative analysis for WASH research and practice. J. Water Sanit. Hyg. Dev. 2017, 7, 196-208. [CrossRef]

61. Mallick, B.; Rahaman, K.R.; Vogt, J. Coastal livelihood and physical infrastructure in Bangladesh after cyclone Aila. Mitig. Adapt. Strateg. Glob. Chang. 2011, 16, 629-648. [CrossRef]

62. Lizarralde, G.; Root, D. The informal construction sector and the inefficiency of low cost housing markets. Constr. Manag. Econ. 2008, 26, 103-113. [CrossRef]

63. Lizarralde, G.; Tomiyoshi, S.; Bourgault, M.; Malo, J.; Cardosi, G. Understanding differences in construction project governance between developed and developing countries. Constr. Manag. Econ. 2013, 31, 711-730. [CrossRef]

64. Tobin, G.A. Sustainability and community resilience: The holy grail of hazards planning? Glob. Environ. Chang. Part B Environ. Hazards 1999, 1, 13-25. [CrossRef]

65. Bocchini, P.; Frangopol, D.M.; Ummenhofer, T.; Zinke, T. Resilience and sustainability of civil infrastructure: Toward a unified approach. J. Infrastruct. Syst. 2013, 20, 1-16. [CrossRef] 
66. Rodriguez-Nikl, T. Linking disaster resilience and sustainability. Civ. Eng. Environ. Syst. 2015, 32, 157-169. [CrossRef]

67. Cutter, S.L. The landscape of disaster resilience indicators in the USA. Nat. Hazards 2016, 80, 741-758. [CrossRef]

68. United Nations Office for Disaster Risk Reduction. Sendai Framework for Disaster Risk Reduction 2015-2030; United Nations Office for Disaster Risk Reduction: Geneva, Switzerland, 2015.

69. Ki-moon, B. One Humanity: Shared Responsibility Report of the Secretary-General for the World Humanitarian Summit; United Nations: New York, NY, USA, 2016. 